\title{
Mechanical ventilation affects alveolar fibrinolysis in LPS-induced lung injury
}

\author{
P. Dahlem*,\# , A.P. Bos\#, J.J. Haitsma*, ${ }^{*}$, M.J. Schultz ${ }^{\mp,+}$, E.K. Wolthuis ${ }^{+}$, \\ J.C.M. Meijers ${ }^{\S}$ and B. Lachmann*
}

ABSTRACT: The aim of the present study was to determine the effects of mechanical ventilation on alveolar fibrin turnover in lipopolysaccharide (LPS)-induced lung injury.

In a randomised controlled trial, Sprague-Dawley rats $(n=61)$ were allocated to three ventilation groups after intratracheal LPS (Salmonella enteritidis) instillations. Group I animals were subjected to $16 \mathrm{cmH}_{2} \mathrm{O}$ positive inspiratory pressure (PIP) and $5 \mathrm{cmH}_{2} \mathrm{O}$ positive end-expiratory pressure (PEEP); group II animals to $26 \mathrm{cmH}_{2} \mathrm{O}$ PIP and $5 \mathrm{cmH}_{2} \mathrm{O}$ PEEP; and group III animals to $35 \mathrm{cmH}_{2} \mathrm{O}$ PIP and $5 \mathrm{cmH}_{2} \mathrm{O}$ PEEP. Control rats (not mechanically ventilated) received LPS. Healthy rats served as a reference group. Levels of thrombin-antithrombin complex (TATC), D-dimer, plasminogen activator inhibitor (PAI) activity and PAI-1 antigen in bronchoalveolar lavage fluid were measured.

LPS-induced lung injury increased TATC, D-dimer and PAI activity and PAI-1 antigen levels versus healthy animals. High pressure-amplitude ventilation increased TATc concentrations. D-dimer concentrations were not significantly raised. Instead, PAI activity increased with the amplitude of the pressure, from $0.7 \mathrm{U} \cdot \mathrm{mL}^{-1}$ in group I to $3.4 \mathrm{U} \cdot \mathrm{mL}^{-1}$ in group II and $5.0 \mathrm{U} \cdot \mathrm{mL}^{-1}$ in group III. There was no change in PAl-1 antigen levels.

In conclusion, mechanical ventilation creates an alveolar/pulmonary anti-fibrinolytic milieu in endotoxin-induced lung injury which, at least in part, might be due to an increase in plasminogen activator inhibitor activity.

KEYWORDS: Adult respiratory distress syndrome, animal experimentation, endotoxin, fibrinolysis, mechanical ventilation

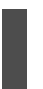
ntra-alveolar fibrin depositions are the pathognomonic hallmark of acute lung injury (ALI) on lung microscopy [1-3]. The fibrin matrix inactivates and incorporates surfactant, leading to severe hypoxaemic respiratory failure $[4,5]$. Alveolar fibrin is part of the inflammatory response seen in ALI and may initiate fibrotic repair with long-term compromised pulmonary function [6, 7]. Intra-alveolar fibrin formation in ALI occurs after capillary alveolar leakage of plasma fibrinogen, activation of coagulation and suppression of local fibrinolysis [7-10]. Alveolar macrophages and alveolar epithelial cells are directly stimulated by bacterial endotoxins or indirectly by pro-inflammatory mediators (e.g. tumour necrosis factor (TNF)- $\alpha$ ) to produce procoagulant and anti-fibrinolytic proteins. Activated factor VII and tissue factor on the pro-coagulant side, and plasminogen activator inhibitor (PAI)-1 on the anti-fibrinolytic side, are the main mediators of disturbed fibrin turnover. The degree of alveolar fibrin formation and the persistence of fibrin depend mainly on suppressed fibrinolytic capacity due to increased local production of PAI-1 [3, 7-9, 11-15]. Under normal circumstances, intra-alveolar fibrin is resolved within minutes by plasmin [16] and intact surfactant is released, restoring pulmonary function [17]. During ALI, however, alveolar fibrin turnover is disturbed and aggravated by additional insults (e.g. haemorrhagic shock, infections, ventilator-associated pneumonia) [18, 19]. The present authors recently demonstrated that injurious mechanical ventilation can depress alveolar fibrinolytic capacity in healthy rats after iatrogenic fibrin formation [20]. In the present study, the effects of different ventilation strategies on alveolar fibrinolysis were examined in rats with "pre-injured" lungs due to endotoxininduced lung injury.

\section{MATERIALS AND METHODS}

The present study was approved by the Animal Committee of the Erasmus University Rotterdam (Rotterdam, The Netherlands). Care and handling of the animals were in accordance with

\section{AFFILIATIONS}

*Dept of Anaesthesiology, Erasmus MC-Faculty Rotterdam, Rotterdam, and

\#Emma Children's Hospital, Paediatric Intensive Care Unit ${ }^{+}$Adult Intensive Care Unit, and

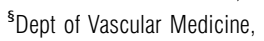
Academic Medical Centre of the University of Amsterdam, Amsterdam, The Netherlands. "Interdepartmental Division of Critical Care, University of Toronto, Toronto, ON, Canada.

CORRESPONDENCE

P. Dahlem

Coburg Medical Centre

Children's Hospital

Ketschendorferstr. 33 96450 Coburg

Germany

Fax: 499561225552

E-mail: PDahlem@hotmail.com

Received:

November 212004

Accepted after revision:

June 302006 
the European Community guidelines. The experiments were performed at the Dept of Anaesthesiology, Erasmus MCFaculty Rotterdam in male Sprague-Dawley rats (IFFA Credo, Someren, The Netherlands; $n=61$ ) with a mean \pm SEM body weight of $283.4 \pm 2.6 \mathrm{~g}$.

\section{Induction of intra-alveolar fibrin formation by local lung inflammation}

Lipopolysaccharide (LPS)-induced lung inflammation, adapted from the model originally described by WHEELDON et al. [21] and VAN HELDEN et al. [22], was brought about in 51 animals by intratracheal instillation of $16 \mathrm{mg} \cdot \mathrm{kg}^{-1} \mathrm{LPS}$, derived from Salmonella enteritidis (L6761; Sigma-Aldrich, St Louis, MO, USA). The procedure was performed after orotracheal intubation under gaseous anaesthesia (65\% nitrous oxide:33\% oxygen:2\% isoflurane; Pharmchemie, Haarlem, The Netherlands), using a miniature nebuliser (Penn-Century, Philadelphia, PA, USA). After the procedure, rats were extubated.

\section{Experimental protocol}

Rats were anaesthetised $24 \mathrm{~h}$ after LPS instillation as detailed earlier and tracheotomised. A catheter was inserted into a carotid artery. Anaesthesia was maintained with hourly i.p. injections of pentobarbital sodium $\left(60 \mathrm{mg} \cdot \mathrm{kg}^{-1}\right.$, Nembutal; Algin BV, Maassluis, The Netherlands). Muscle relaxation was attained with hourly i.m. injections of pancuronium bromide (2 mg $\mathrm{kg}^{-1}$, Pavulon; Organon Technika, Boxtel, The Netherlands). After muscle relaxation, all animals were connected to a ventilator (Servo Ventilator 300; SiemensElema, Solna, Sweden) set in a pressure-controlled mode with positive inspiratory pressure (PIP) of $12 \mathrm{cmH}_{2} \mathrm{O}$, positive endexpiratory pressure (PEEP) of $2 \mathrm{cmH}_{2} \mathrm{O}$, frequency of 30 breaths $\cdot \mathrm{min}^{-1}$, inspiratory/expiratory time ratio of 1:2 and fractional inspired oxygen tension $\left(\mathrm{FI}, \mathrm{O}_{2}\right)$ of 1.0 . Body temperature was kept within normal range by means of a heating pad. After $15 \mathrm{~min}$ of stabilisation, arterial blood gases were taken using a carotid artery catheter and PIP was adjusted according to the ventilation group to which the animals had been allocated. Arterial blood gases were sampled every $30 \mathrm{~min}$ thereafter using conventional methods (ABL555; Radiometer, Copenhagen, Denmark). Mean arterial blood pressure (MAP) was monitored using the intra-arterial carotid artery catheter every $30 \mathrm{~min}$ for $3 \mathrm{~h}$.

\section{Study groups}

Animals were allocated to one of three ventilation groups, each with different pressure amplitude. A PEEP of $5 \mathrm{cmH}_{2} \mathrm{O}$ was selected for all groups, but PIP was different in each group. Group I $(n=12)$ was ventilated with a PIP of $16 \mathrm{cmH}_{2} \mathrm{O}$; group II $(n=13)$ with a PIP of $26 \mathrm{cmH}_{2} \mathrm{O}$; and group III $(n=13)$ with a PIP of $35 \mathrm{cmH}_{2} \mathrm{O}$. The ventilation period was designed to last $3 \mathrm{~h}$, after which final measurements were made. $\mathrm{FI}_{1} \mathrm{O}_{2}$ was kept at 1.0 throughout the study period to prevent hypoxaemia developing in any of the groups.

Control group animals $(n=13)$ received LPS instillations as described previously ("LPS controls"), but were not mechanically ventilated. To create reference values, a group of healthy rats $(n=10)$ did not receive LPS and were not ventilated ("healthy" animals). At the end of the ventilation period, all rats $(n=61)$ were killed with an intra-arterial overdose of pentobarbital sodium $\left(600 \mathrm{mg} \cdot \mathrm{kg}^{-1}\right)$ and all measurements were then made.

\section{Bronchoalveolar lavage}

After the rats were killed, the thorax and diaphragm were opened and lungs removed. As a parameter of lung injury, subsequently lung weight/body weight ratio was calculated. Bronchoalveolar lavage (BAL) was performed with normal saline $\left(30 \mathrm{~mL} \cdot \mathrm{kg}^{-1}\right.$, heated to $\left.37^{\circ} \mathrm{C}\right)$ and re-aspirated three times. BAL fluid (BALF) was centrifuged $(400 \times g$ for $10 \mathrm{~min}$ at $4{ }^{\circ} \mathrm{C}$ ) and the recovered supernatant fluid was snap-frozen and stored at $-80^{\circ} \mathrm{C}$ until further processing. Measurements were not completed in two rats of group II and in three rats of group III, owing to air leakage during the test.

\section{Measurements}

Coagulation activation, as assessed by thrombin-antithrombin complexes (TATc), was measured in BALF with an ELISAbased method. Briefly, rabbits were immunised with mouse thrombin or rat antithrombin. Antithrombin antibodies were used as a capture antibody; digoxigenin-conjugated antiantithrombin antibodies were used as detection antibodies; horseradish peroxidase-labelled sheep anti-digoxigenin antigenbinding fragments (Boehringer Mannheim, Mannheim, Germany) were used as staining enzyme, and o-phenylenediamine dihydrochloride (Sigma-Aldrich) was used as substrate. Dilutions of mouse serum (Sigma-Aldrich) were used for the standard curve, yielding a lower detection limit of $0.3 \mathrm{ng} \cdot \mathrm{mL}^{-1}$ [23].

Fibrin breakdown of LPS-induced alveolar fibrin formation was determined by measurements of D-dimers (cross-linked fibrin degradation products) in BALF [24]. D-dimers were quantitated by a sandwich-type ELISA (Asserachrom D-dimer; Diagnostica Stago, Asnières-sur-Seine, France). This assay shows cross-reactivity with rat D-dimers.

PAI activity in BALF was determined using an automated coagulation analyser (Behring Coagulation System; Dade Behring, Marburg, Germany) with reagents and protocols from the manufacturer. This assay determines the urokinaseinhibiting activity of the sample. The remaining urokinase is then assayed by activating plasminogen to plasmin and subsequently determining plasmin chromogenic activity. The assay is independent of variable concentrations of plasminogen, $\alpha$-2-antiplasmin and fibrinogen in the sample. The upper detection limit of this test is set at $6.9 \mathrm{U} \cdot \mathrm{mL}^{-1}$. Protein concentration in BALF was measured using the Bradford method (Bio-Rad protein assay; Bio-Rad Laboratories, Munich, Germany [25].

To determine the levels of PAI-1 antigen in BALF, a rat PAI-1 ELISA was developed using a rabbit polyclonal antibody (Abcam Ltd, Cambridge, UK) as coating antibody and a biotinylated rabbit immunoglobulin G antibody (Molecular Innovations Inc., Southfield, MI, USA) as developing antibody. Rat PAI-1 (Calbiochem, La Jolla, CA, USA) was used as a standard.

To illustrate alveolar fibrin depositions, samples were taken from all lung lobes and 30 fields were analysed. The analysing pathologist was not informed about the purpose of the study and was asked to prepare rat lungs for illustration of alveolar 
fibrin deposition. Histological analysis was performed as previously described [20]. Briefly, lungs were fixed at $10 \mathrm{cmH}_{2} \mathrm{O} \mathrm{MAP}$, and slices were stained for fibrinogen. During the washing procedure, fibrinogen would have been washed out leaving solely fibrin attached to the alveolar wall. Slides of lung tissue were deparaffinised and endogenous peroxidase activity was quenched by a solution of methanol/ $0.03 \% \mathrm{H}_{2} \mathrm{O}_{2}$ (Merck, Darmstadt, Germany). After digestion with a $0.25 \%$ weight/volume solution of pepsin (SigmaAldrich) in $0.01 \mathrm{M} \mathrm{HCl}$, the sections were incubated in $10 \%$ normal goat serum (Dako, Glostrup, Denmark) and then exposed to biotin-labelled goat anti-human fibrinogen antibody (Accurate Chemical \& Scientific Corporation, Westbury, NY, USA). After washes, slides were then incubated in a streptavidin-ABC solution (Dako) and developed using 1\% $\mathrm{H}_{2} \mathrm{O}_{2}$ and 3.3'-diaminobenzidin-tetra-hydrochloride (SigmaAldrich) in Tris- $\mathrm{HCl}$. The sections were mounted in glycerine gelatin and counterstained with haematoxylin.

\section{Statistical analysis}

Data are presented as mean \pm SEM. Group differences were analysed with ANOVA, while differences between the three ventilated groups were analysed using a Kruskall-Wallis test. Differences between the healthy and LPS control group, and between the ventilated groups and the LPS control group, were analysed with a Mann-Whitney U-test. A p-value $<0.05$ was considered significant.

In table 1, all values for TATc, D-dimer, PAI activity and PAI-1 antigen were corrected for their individual corresponding protein levels. Analysis was performed as described previously.

\section{RESULTS}

All animals survived the study period. LPS instillation caused severe respiratory distress with tachypnoea and significant weight loss, from $283.4 \pm 2.6 \mathrm{~g}$ before LPS instillation to a mean of $260.3 \pm 2.6 \mathrm{~g}(\mathrm{p}<0.001) 24 \mathrm{~h}$ after LPS instillation.

Mechanical ventilation with high pressure amplitudes caused lung injury with compromised partial pressure of oxygen in arterial blood $\left(\mathrm{Pa}_{\mathrm{a}} \mathrm{O}_{2}\right)$; group III showed lower $\mathrm{Pa}_{\mathrm{a}} \mathrm{O}_{2}$ values compared with group I at 120, 150 and $180 \mathrm{~min}$ (fig. 1 ; p < 0.05). Furthermore, animals in ventilation group II (pre-study MAP $124 \pm 6 \mathrm{mmHg}$ versus end-of-study MAP $105 \pm 6 \mathrm{mmHg}$; $\mathrm{p}<0.05$ ) and ventilation group III (pre-study MAP $126 \pm 4 \mathrm{mmHg}$ versus end-of-study MAP $73 \pm 5 \mathrm{mmHg}$, $\mathrm{p}<0.001$ ), ventilated with high pressure amplitudes, showed lower MAP values at the end of the study period. At the end of the experiment, the extent of lung injury was also evidenced by a significant increase in median lung weight/body weight in group II of $9.2 \pm 0.4 \mathrm{~g} \cdot \mathrm{kg}^{-1}$ and in group III of $13.3 \pm 0.8 \mathrm{~g} \cdot \mathrm{kg}^{-1}$, versus $7.8 \pm 0.6 \mathrm{~g} \cdot \mathrm{kg}^{-1}$ in animals from group I (table 1 ).

\section{Coagulation activation}

LPS instillation resulted in activation of coagulation. TATc levels increased from $3.3 \pm 1.0 \mathrm{ng} \cdot \mathrm{mL}^{-1}$ in healthy animals to $78.6 \pm 15.2 \mathrm{ng} \cdot \mathrm{mL}^{-1}$ in LPS-treated animals (fig. 2). Increased pressure amplitude resulted in a significant increase in TATc

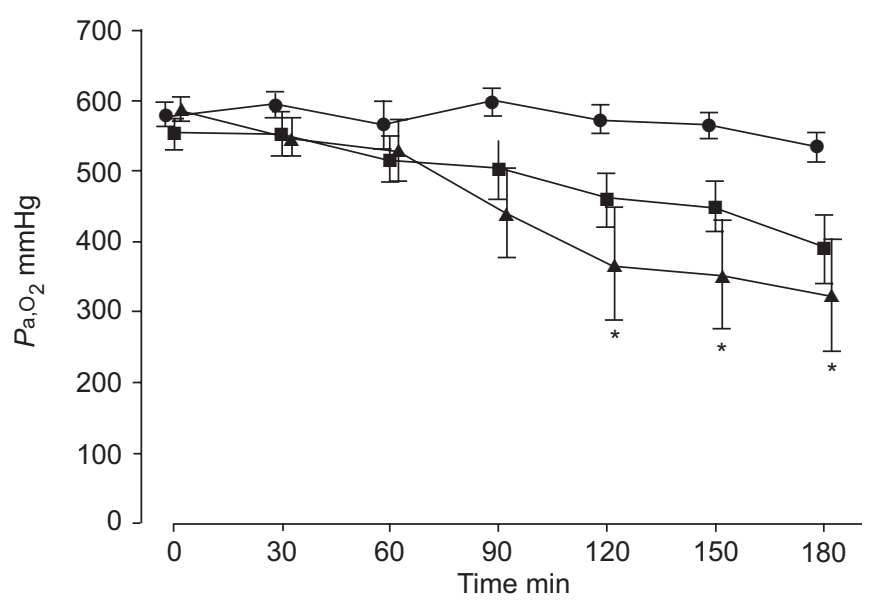

FIGURE 1. The effect of mechanical ventilation on partial pressure of oxygen in arterial blood $\left(\mathrm{Pa}, \mathrm{O}_{2}\right)$ over time in the three ventilated groups. $\bullet$ : group I; $\mathbf{\square}$ : group II; $\boldsymbol{\Delta}$ : group III. *: $p<0.05$ versus group I. $1 \mathrm{mmHg}=0.133 \mathrm{kPa}$.

TABLE 1 Lung weight, total bronchoalveolar lavage fluid (BALF) protein levels and values for thrombin-antithrombin complex (TATC), D-dimer, plasminogen activator inhibitor (PAl) activity and PAl-1 antigen adjusted for protein levels in BALF

\begin{tabular}{|c|c|c|c|c|c|c|}
\hline & Healthy & LPS controls & Group I & Group II & Group III & $\begin{array}{c}\text { p-value between ventilated } \\
\text { groups }\end{array}$ \\
\hline Animals $\mathbf{n}$ & 8 & 11 & 11 & 12 & 12 & \\
\hline $\begin{array}{l}\text { Lung weight/body weight } \\
\qquad \mathrm{g} \cdot \mathrm{kg}^{-1}\end{array}$ & $6.0 \pm 0.4$ & $8.1 \pm 0.3^{*}$ & $7.8 \pm 0.6$ & $9.2 \pm 0.4$ & $13.3 \pm 0.8^{\#}$ & 0.01 \\
\hline Total protein $\mathrm{mg} \cdot \mathrm{mL}^{-1}$ & $0.09 \pm 0.01$ & $0.7 \pm 0.11^{\star}$ & $0.54 \pm 0.06$ & $0.67 \pm 0.07$ & $1.02 \pm 0.12$ & 0.01 \\
\hline TATc/total protein $\mathbf{n g} \cdot \mathrm{mg}^{-1}$ & $42.6 \pm 13.7$ & $116 \pm 15.8^{*}$ & $85.1 \pm 6.6$ & $74.7 \pm 6.9$ & $67.6 \pm 9.7$ & 0.23 \\
\hline $\mathrm{D}$-dimer/total protein $\mu \mathrm{g} \cdot \mathrm{mg}^{-1}$ & $21.8 \pm 7.2$ & $22.2 \pm 4.2$ & $88.6 \pm 35.2^{\#}$ & $62.7 \pm 7.9^{\#}$ & $56.3 \pm 13.4$ & 0.76 \\
\hline $\begin{array}{l}\text { PAl activity/total protein } \\
\mathrm{U} \cdot \mathrm{mg}^{-1}\end{array}$ & $0.0 \pm 0.0$ & $0.9 \pm 0.6^{*}$ & $1.1 \pm 0.7$ & $4.4 \pm 0.9^{\#}$ & $5.3 \pm 0.7^{\#}$ & 0.005 \\
\hline $\begin{array}{l}\text { PAl-1 antigen/total protein } \\
\text { ng } \cdot \mathrm{mg}^{-1}\end{array}$ & $0.3 \pm 0.2$ & $19 \pm 2.3^{*}$ & $25.3 \pm 4.2$ & $24.9 \pm 2.6$ & $18.3 \pm 3.1$ & 0.23 \\
\hline
\end{tabular}

Data are presented as mean \pm SEM, unless otherwise stated. Adjustments were made for protein content in BALF per individual sample. LPS: lipopolysaccharide. *: $\mathrm{p}<0.05$ versus healthy controls; ${ }^{*}: \mathrm{p}<0.05$ versus LPS controls. 
levels between the three ventilated groups (fig. 2). Only TATc levels in group I animals were significantly lower compared with LPS controls (fig. 2).

\section{Fibrinolysis}

In LPS controls, absolute D-dimer levels in BALF were $13.4 \pm 2.0 \mu \mathrm{g} \cdot \mathrm{L}^{-1}$, compared with $1.8 \pm 0.6 \mu \mathrm{g} \cdot \mathrm{L}^{-1}$ in healthy rats $(p<0.001)$, indicating alveolar fibrin formation caused by endotoxin (fig. 2). Mechanical ventilation increased D-dimer levels in BALF compared with LPS control animals. Different ventilation pressure amplitudes did not significantly alter Ddimer levels between groups I-III; group I D-dimer levels were $36.1 \pm 8.3 \mu \mathrm{g} \cdot \mathrm{L}^{-1}$, versus $65.8 \pm 16.9 \mu \mathrm{g} \cdot \mathrm{L}^{-1}$ in group III.

\section{Anti-fibrinolysis}

PAI activity was undetectable in BALF of healthy rats and was $1.24 \pm 0.8 \mathrm{U} \cdot \mathrm{mL}^{-1}$ in LPS controls (fig. 2). Between the ventilated groups, PAI activity levels were significantly increased; PAI activity concentrations in BALF were $0.7 \pm 0.5 \mathrm{U} \cdot \mathrm{mL}^{-1}$, $3.4 \pm 0.8 \mathrm{U} \cdot \mathrm{mL}^{-1}$ and $5.0 \pm 0.7 \mathrm{U} \cdot \mathrm{mL}^{-1}$ in groups I, II and III, respectively (fig. 2). PAI activity in group III was also significantly different from that in LPS control animals. Minimal levels of PAI-1 antigen were detected in healthy animals $\left(0.03 \pm 0.02 \mathrm{ng} \cdot \mathrm{mL}^{-1}\right)$, but instillation of LPS led to a significant rise in PAI-1 antigen $\left(13.9 \pm 3.6 \mathrm{ng} \cdot \mathrm{mL}^{-1} ; \mathrm{p}<0.05\right.$; fig. 2). There was no difference in PAI-1 antigen levels between the three ventilated groups, or between the ventilated groups and the LPS control animals (fig. 2).

\section{Histology}

In figure 3 , microscopy of representative rat lung tissue shows lung inflammation caused by LPS. In all ventilated animals, unresolved fibrin depositions (fig. $3 c$ and d) were observed. More fibrin deposits were observed in animals ventilated with the highest pressure amplitude, although there were no differences in levels of lung inflammation. Atelectasis was also more pronounced in animals of group II and especially group III.

\section{DISCUSSION}

The present study investigated the effect of mechanical ventilation on alveolar fibrinolysis in LPS-induced lung injury. Intratracheal LPS instillation caused local activation of coagulation, with an increase in TATc levels with fibrin formation (as documented by the appearance of D-dimer in BALF of animals of the LPS control group). The occurrence of alveolar fibrin formation after LPS-induced lung inflammation has been documented previously in a comparable experimental model [24].
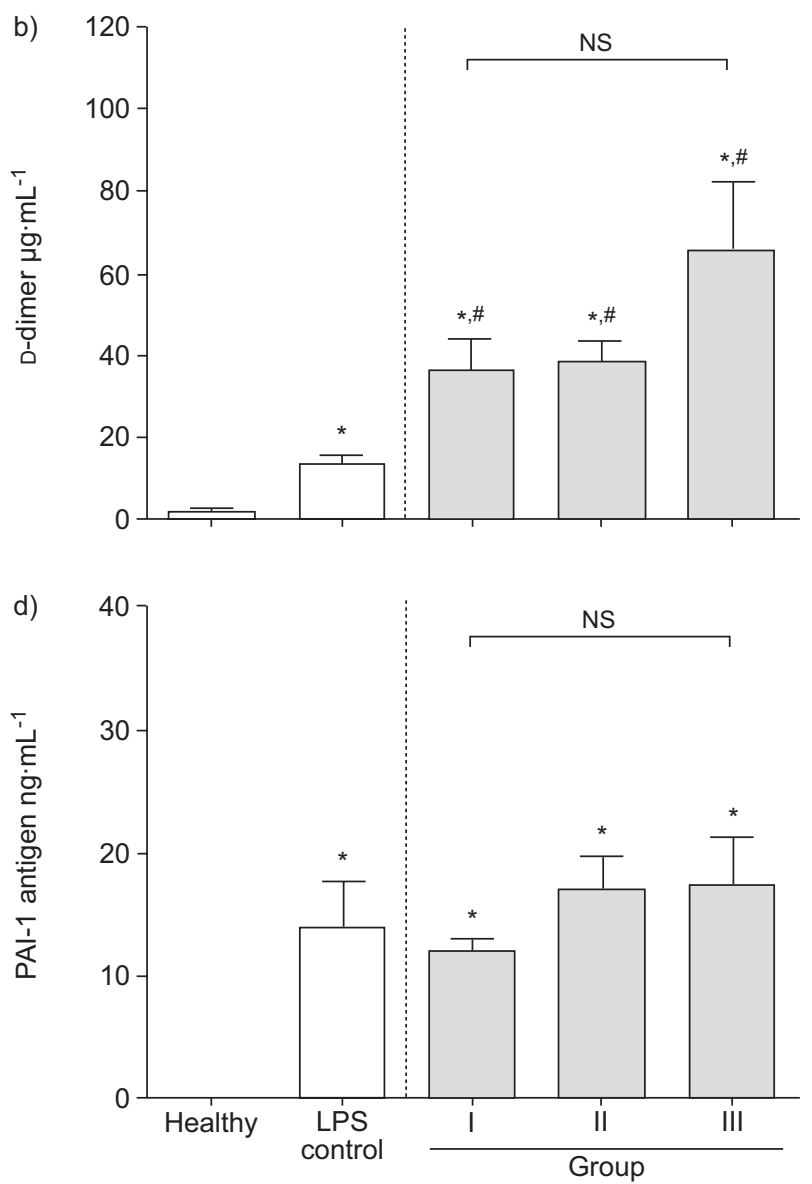

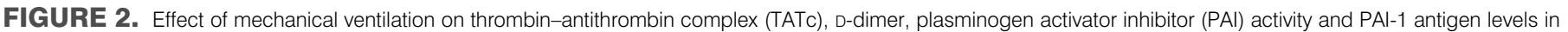

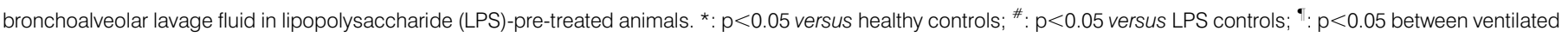
groups. 

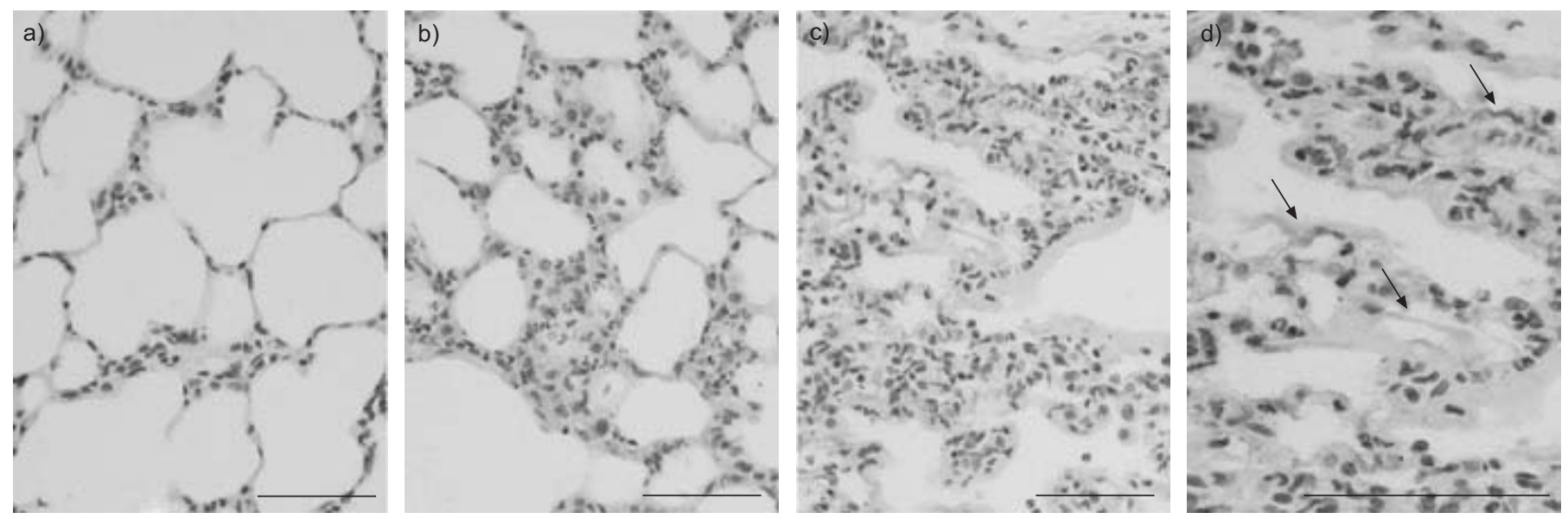

FIGURE 3. Microscopy of representative fibrin-stained paraffin sections of rat lung tissue of lipopolysacchride (LPS)-treated rats. a) Normal lung tissue; b) lung tissue of a representative sample of the LPS control group ( $24 \mathrm{~h}$ after LPS instillation) predominantly showing interstitial infiltrates with neutrophils; c) representative lung tissue of group III, showing interstitial infiltrates with neutrophils and unresolved fibrin/fibrinogen depositions (counterstained with haematoxylin) after 3-h mechanical ventilation; and d) a close-up of c), showing unresolved fibrin/fibrinogen depositions (arrows). Scale bars $=0.1 \mathrm{~mm}$.

Mechanical ventilation aggravates this endotoxin-induced lung inflammation and might therefore influence alveolar fibrin turnover [26]. Therefore, the experimental model of the present study may be considered an appropriate model for the study of the effects of mechanical ventilation on alveolar fibrinolysis.

Acute lung injury is characterised by alveolar flooding. Ventilator-induced lung injury aggravates or may even be the cause of this flooding [27]. In the present study, pulmonary oedema formation was also observed, as characterised by the BALF protein levels and increased lung weights of the animals ventilated with higher pressure amplitudes.

D-dimer concentrations in the BALF of the ventilated animals were higher than in LPS controls. However, there were no significant differences between the ventilation groups. In contrast, PAI activity increased with the size of the pressure amplitude, without a change in PAI-1 antigen levels. The present results link injurious ventilation settings in inflamed lungs with depressed fibrinolysis for the first time. Furthermore, independent of protein leakage into the lung, injurious mechanical ventilation increased the PAI activity in BALF.

The current authors observed an increase in PAI activity but did not see an increase in PAI antigen levels. Conversion of PAI-1 between its active and latent forms is regulated by vitronectin, which circulates in plasma but is also a major constituent of the extracellular matrix [28, 29]. In the data adjusted for total protein levels, an increase in activity without a change in antigen levels was still observed, suggesting that PAI activity is dependent on protein/vitronectin influx and subsequent stabilisation of PAI activity during high pressureamplitude ventilation.

Surprisingly, increased PAI activity did not result in lower amounts of D-dimer in BALF. There might be two possible explanations. First, 3-h mechanical ventilation might not be enough to demonstrate a larger effect on the downregulation of alveolar fibrin breakdown due to PAI production. Secondly, the high D-dimer levels in the BALF of group III animals (although not significantly different compared with the other ventilated groups, despite high PAI activity) might be explained by additional alveolar fibrin formation, triggered by traumatic mechanical ventilation and an influx of plasma proteins. It is impossible in the current experiment to distinguish whether the increased levels of D-dimers reflect increased fibrinolysis only, or whether they also reflect a higher level of pro-coagulation, resulting in increased formation of fibrin, which will translate into increased D-dimer levels.

The idea of extra fibrin formation in a second-hit model of lung injury (endotoxin plus mechanical ventilation) is plausible. Under both circumstances, similar inflammatory mediators are expressed (e.g. TNF- $\alpha$ ), which may activate the intra-alveolar coagulation system and fibrin formation [18, 30]. LPS induces coagulation activation as indicated by increased TATc levels, whereas mechanical ventilation with low pressure amplitudes significantly reduced this. A possible explanation for this phenomenon is that, with higher pressure amplitudes, resolution of coagulation is impaired.

Despite these questions concerning the levels of D-dimer in BALF, the interpretation of the PAI values is striking. Aggressive mechanical ventilation can upregulate PAI, the strongest antifibrinolytic mediator, which might contribute to the persistence of alveolar fibrin and aggravate lung injury (e.g. lung fibrosis). The clinical importance of PAI-1 upregulation in mechanically ventilated patients has only recently been reported [31]. In adult ALI patients, high levels of PAI-1 in pulmonary oedema fluid have been associated with an increase in mortality [31].

The fact that mechanical ventilation may affect the alveolar fibrinolytic milieu has been demonstrated previously [20]. However, in that study, alveolar fibrin formation was generated by instillations of fibrinogen/thrombin in healthy rats, whereas in the present study the amount of alveolar fibrin formation was dependent on the endogenous capability of 
each animal to build alveolar fibrin after the LPS challenge. A recent report on early stress-response genes demonstrated that coagulation genes are upregulated during ventilation-induced lung injury [32].

The major limitation of the present study is that it was not possible to determine the origin of the fibrin deposits, or more accurately the breakdown product D-dimers, in the BALF. The immunohistochemistry data do not allow the present authors to distinguish between fibrin or fibrinogen in the alveolar, capillary or interstitial space. Despite this, the D-dimer values in BALF clearly demonstrate increased breakdown of intraalveolar fibrin deposits during mechanical ventilation, suggesting increased fibrin deposits in the alveolar space.

In summary, the present study provides new information showing that mechanical ventilation influences alveolar plasminogen activator inhibitor activity after endotoxin exposure and can influence alveolar fibrionolysis. Future experimental studies are needed to elucidate the underlying mechanisms.

\section{ACKNOWLEDGEMENTS}

The authors would like to thank S. Krabbendam for expert technical assistance (Dept of Anaesthesiology, Erasmus MCFaculty Rotterdam, Rotterdam, The Netherlands), M. Weijne for laboratory assistance (Dept of Vascular Medicine), $\mathrm{H}$. Thygesen for statistical advice (Dept of Biostatistics and Epidemiology), L.A. Noorduyn for histological expert preparation (Dept of Pathology; all University of Amsterdam, Amsterdam, The Netherlands) and L. Visser-Isles for Englishlanguage corrections (Erasmus Medical Faculty).

\section{REFERENCES}

1 Bachofen M, Weibel ER. Structural alterations of lung parenchyma in the adult respiratory distress syndrome. Clin Chest Med 1982; 3: 35-56.

2 Ashbaugh DG, Bigelow DB, Petty TL, Levine BE. Acute respiratory distress in adults. Lancet 1967; 2: 319-323.

3 Idell S. Extravascular coagulation and fibrin deposition in acute lung injury. New Horiz 1994; 2: 566-574.

4 Seeger W, Elssner A, Gunther A, Kramer HJ, Kalinowski HO. Lung surfactant phospholipids associate with polymerizing fibrin: loss of surface activity. Am J Respir Cell Mol Biol 1993; 9: 213-220.

5 Seeger W, Stohr G, Wolf HR, Neuhof H. Alteration of surfactant function due to protein leakage: special interaction with fibrin monomer. J Appl Physiol 1985; 58: 326-338.

6 Fukuda Y, Ishizaki M, Masuda Y, Kimura G, Kawanami O, Masugi $Y$. The role of intraalveolar fibrosis in the process of pulmonary structural remodeling in patients with diffuse alveolar damage. Am J Pathol 1987; 126: 171-182.

7 Idell S. Coagulation, fibrinolysis, and fibrin deposition in acute lung injury. Crit Care Med 2003; 31: Suppl. 4, S213-S220.

8 Levi M, Schultz MJ, Rijneveld AW, van der Poll T. Bronchoalveolar coagulation and fibrinolysis in endotoxemia and pneumonia. Crit Care Med 2003; 31: Suppl. 4, S238-S242.
9 Welty-Wolf KE, Carraway MS, Ortel TL, Piantadosi CA. Coagulation and inflammation in acute lung injury. Thromb Haemost 2002; 88: 17-25.

10 Schultz MJ, Haitsma JJ, Zhang H, Slutsky AS. Pulmonary coagulopathy as a new target in therapeutic studies of acute lung injury or pneumonia - a review. Crit Care Med 2006; 34: 871-877.

11 Idell S. Endothelium and disordered fibrin turnover in the injured lung: newly recognized pathways. Crit Care Med 2002; 30: Suppl. 5, S274-S280.

12 van der Poll T, de Jonge E, Levi M. Regulatory role of cytokines in disseminated intravascular coagulation. Semin Thromb Hemost 2001; 27: 639-651.

13 Barazzone C, Belin D, Piguet PF, Vassalli JD, Sappino AP. Plasminogen activator inhibitor-1 in acute hyperoxic mouse lung injury. J Clin Invest 1996; 98: 2666-2673.

14 Bertozzi P, Astedt B, Zenzius L, et al. Depressed bronchoalveolar urokinase activity in patients with adult respiratory distress syndrome. N Engl J Med 1990; 322: 890-897.

15 Idell S, James KK, Levin EG, et al. Local abnormalities in coagulation and fibrinolytic pathways predispose to alveolar fibrin deposition in the adult respiratory distress syndrome. J Clin Invest 1989; 84: 695-705.

16 Chung SI, Lee SY, Uchino R, Carmassi F. Factors that control extravascular fibrinolysis. Semin Thromb Hemost 1996; 22: 479-488.

17 Gunther A, Kalinowski M, Elssner A, Seeger W. Clotembedded natural surfactant: kinetics of fibrinolysis and surface activity. Am J Physiol 1994; 267: L618-L624.

18 Schultz MJ, Millo J, Levi M, et al. Local activation of coagulation and inhibition of fibrinolysis in the lung during ventilator associated pneumonia. Thorax 2004; 59: 130-135.

19 Fan J, Kapus A, Li YH, Rizoli S, Marshall JC, Rotstein OD. Priming for enhanced alveolar fibrin deposition after hemorrhagic shock: role of tumor necrosis factor. Am J Respir Cell Mol Biol 2000; 22: 412-421.

20 Dahlem P, Bos AP, Haitsma JJ, Schultz MJ, Meijers JC, Lachmann B. Alveolar fibrinolytic capacity suppressed by injurious mechanical ventilation. Intensive Care Med 2005; 31: 724-732.

21 Wheeldon EB, Walker ME, Murphy DJ, Turner CR. Intratracheal aerosolization of endotoxin in the rat: a model of the adult respiratory distress syndrome (ARDS). Lab Anim 1992; 26: 29-37.

22 van Helden $\mathrm{HP}$, Kuijpers WC, Steenvoorden D, et al. Intratracheal aerosolization of endotoxin (LPS) in the rat: a comprehensive animal model to study adult (acute) respiratory distress syndrome. Exp Lung Res 1997; 23: 297-316.

23 Rijneveld AW, Weijer S, Florquin S, et al. Thrombomodulin mutant mice with a strongly reduced capacity to generate activated protein $C$ have an unaltered pulmonary immune response to respiratory pathogens and lipopolysaccharide. Blood 2004; 103: 1702-1709.

24 Sato N, Takahashi H, Shibata A. Fibrinogen/fibrin degradation products and D-dimer in clinical practice: interpretation of discrepant results. Am J Hematol 1995; 48: 168-174.

25 Bradford MM. A rapid and sensitive method for the quantitation of microgram quantities of protein utilizing 
the principle of protein-dye binding. Anal Biochem 1976; 72: 248-254.

26 Vreugdenhil HA, Haitsma JJ, Jansen KJ, et al. Ventilatorinduced heat shock protein 70 and cytokine mRNA expression in a model of lipopolysaccharide-induced lung inflammation. Intensive Care Med 2003; 29: 915-922.

27 Verbrugge SJ, Vazquez de Anda G, Gommers D, et al. Exogenous surfactant preserves lung function and reduces alveolar Evans blue dye influx in a rat model of ventilationinduced lung injury. Anesthesiology 1998; 89: 467-474.

28 Lazar MH, Christensen PJ, Du M, et al. Plasminogen activator inhibitor-1 impairs alveolar epithelial repair by binding to vitronectin. Am J Respir Cell Mol Biol 2004; 31: 672-678.

29 Ngo TH, Hoylaerts MF, Knockaert I, Brouwers E, Declerck PJ. Identification of a target site in plasminogen activator inhibitor-1 that allows neutralization of its inhibitor properties concomitant with an allosteric upregulation of its antiadhesive properties. J Biol Chem 2001; 276: 26243-26248.

30 Gunther A, Mosavi P, Heinemann S, et al. Alveolar fibrin formation caused by enhanced procoagulant and depressed fibrinolytic capacities in severe pneumonia. Comparison with the acute respiratory distress syndrome. Am J Respir Crit Care Med 2000; 161: 454-462.

31 Prabhakaran P, Ware LB, White KE, Cross MT, Matthay MA, Olman MA. Elevated levels of plasminogen activator inhibitor-1 in pulmonary edema fluid are associated with mortality in acute lung injury. Am J Physiol Lung Cell Mol Physiol 2003; 285: L20-L28.

32 Ma SF, Grigoryev DN, Taylor AD, et al. Bioinformatic identification of novel early stress response genes in rodent models of lung injury. Am J Physiol Lung Cell Mol Physiol 2005; 289: L468-L477. 